Peer-Reviewed Article

\title{
Rethinking Library Services for First-Generation Students: Using Habitus as a Framework for Reevaluating Existing Models
}

Jordan S. Sly, University of Maryland

Ashleigh D. Coren, Smithsonian Institution

\begin{abstract}
This paper explores the results of our research into the needs of primarily first-generation students as they begin their college careers. We seek to understand attitudinal dimensions regarding retention and how first-generation students perceive libraries and library services as a touchpoint in their education. Particular to this study is our utilization of Pierre Bourdieu's notion of Habitus as a founding theoretical framework. By using this theory, we are able to turn student input into a useful model while maintaining the individuality of the student and also attempting to dissuade harmful and problematic notions of essentialism. This project additionally explores tenets of Critical Librarianship like self-reflection, critical thinking, and examination of teaching practices.

\section{KEYWORDS}

first-generation students, critical librarianship, critical pedagogy
\end{abstract}

\section{SUGGESTED CITATION}

Sly, J., \& Coren, A. (2022). Rethinking library services for first-generation students: using Habitus as a framework for reevaluating existing models. Journal of New Librarianship, 7(1), 126-158. https://doi.org/10.33011/newlibs/11/13

This is an Open Access article distributed under the terms of the Creative Commons Attribution 4.0 International License (http://creativecommons.org/licenses/by/4.0), which permits unrestricted use, distribution, and reproduction in any medium, provided the original work is properly cited. 
In a recent Chronicle of Higher Education article, Beth McMurtrie discusses the experience Gail Horowitz - then a Brooklyn College instructor of Chemistry — found when working with first-generation students. Horowitz found that despite the equal effort firstgeneration students applied to their work, a gap between their work and the college normative students in her class developed. Horowitz identified that it was not simply a matter of intelligence, skill, or effort, but that there were certain cultural practices being employed by the college normative students that were not known by the first-generation students. Additionally, Horowitz noted that the first-generation students "carry the burden of imposter syndrome," which discourages them from looking to professors and other educational support offices. Horowitz correctly identifies many of the factors that may contribute to anxiety and academic problems for first-generation students but approaches the discrepancy as a problem to be solved (McMurtrie, 2019) ${ }^{1}$. As we will explore in this article, we hope to develop a more culturally reflective and responsive approach to developing library-based programming for firstgeneration students that seeks to highlight positive elements of their experience and to challenge the hegemonic acceptance of college normative behaviors. To achieve this, we have approached this project from a framework of critical librarianship utilizing the sociological theory of Habitus to inform the development of a survey which provided an academic profile of the student participants. Applying critical theory does not have to necessitate a strict adherence to typological models but can provide a guiding philosophy and a way of seeing that opens new questions and adds significance to otherwise overlooked variables. In other words, Habitus is not a template for creating new models of instruction, but the questions that can arise from the use of critical models can improve the depth of understanding student needs.

For our study, we have chosen Pierre Bourdieu's Habitus as a model. In short, Habitus refers to the social, cultural, economic, and educational Capital of an individual and their effect on various Fields. Through our study, we hope to apply his theory to demonstrate a mode of thinking about the flexibility of thought that dissuades harmful and problematic notions of essentialism - that is, the condensing of complexity into convenient stereotypes of firstgeneration students. This is an area of discomfort and one reliant on self-conscious reflection as we both collect data on students - an activity of inherent compression - and seek to indicate factors for model development an -activity of passive essentialism. Our goals are not to simply create a formula for librarians to work with first-generation students, but to add a case study to the growing literature that questions current approaches to the pedagogical design of library instruction and outreach programming with a fuller understanding of the whole student. Our use of Bourdieu's theory provides us with a particular approach for understanding notions of coded fields. In this case, our goal is to help bridge some of the potential gaps between the

\footnotetext{
${ }^{1}$ See also, Horowitz, G. (2019). Teaching stem to first generation college students: A guidebook for faculty \& future faculty. Charlotte, NC: Information Age Publishing.
} 
languages of two particular fields: that of the college normative student and their perceived causal accrual of academic language and expectations, and those potentially less accustomed to certain elements of college life and therefore success. As our data suggest, there are perceived and projected normative values indicated through the responses of the participant group and a potentially associated anxiety relating to feelings of inadequacy stemming, perhaps, from issues relating to cultural field transition.

Habitus can be most simply described as the cultural language one is most fluent in. This cultural language then affects one's perceptions of both normative and novel fields which an individual encounters. More specifically, these are the codes, assumptions, affectations, accents, clothing, attitudes, language, values, and other embodied traits that are resultant from how external factors are developed and translated through a cultural lens and projected outward. These are summarized as social, cultural, economic, and educational Capital and each area has a defined set of codes which identifies aspects about that person. These aspects of the "cultural language" or Capital signal to others where that individual fits within a group and within that group's rules or Doxa. These groups are the Fields which an individual must find themselves based on what is available to them via these Doxa. This all comes down to assumption based on how well the individual's Capital aligns with the Field's rules in order to indicate the success of that individual's Practice. Bourdieu illustrates this mechanism mostly clearly in Distinction, despite the implications of his perhaps overly class-based construction of cultural value. Bourdieu essentially posits that a person's Habitus is defined by the ability to fit Capital with Field via Doxa to equal a particular practice (Bourdieu, 1984).

The origins of this project stem from an insultingly deterministic reading of firstgeneration student retention rates and the belief of an administrator that these students lacked the ability to compete with college-normative students ${ }^{2}$. While there are possible differences between college normative students and students for whom college was a foregone conclusion possibly based on socio-economic factors, these differences are not indicative of intelligence or ability, but of resources, familiarity with successful practice, and the negative effects of neoliberalism on the higher education sphere (i.e. the commodification of education both in terms of university revenue and the role of higher education in the broader economy). To simplify, college-normative students are understood to have previous experience with and exposure to a culture that understood the capital gained through higher education, or at least expected the capital gained through college and whose parents most likely work and exist in a field with those same expectations. On the other side of the net are the first-generation students for whom the field of college represents a different set of social and economic capital and

\footnotetext{
2 For further explanation of these core elements of Habitus and the relationship to successful matriculation and a fuller explanation of the project's origins, see my article Sly, J. "Bourdieu's First Year." 2018. Journal of New Librarianship 3 (2): 193-98. doi:10.21173/newlibs/5/4.
} 
cultural language. In one sense there could be a literal language difference in students from nonnative English-speaking families, but there is also the notion that there are a number of cultural or Capital assumptions, that the college normative students will have learned through a combination of family conversation and school expectation. In other words, college normative students may simply be more familiar with the various terms we in education casually throw around from advisor to student union to interlibrary loan and more. This is not a fault; this is a challenge for educators and institutions. These doxa, these unspoken yet critical elements make up the rules for successful practice and if first-generation students are missing elements based on the knowledge unofficially passed in non-academic settings, it could contribute to some of the issues we see with retention. There isn't one reason why students of any background leave college but by helping connect students to resources, campus life, and help in minimizing feelings of imposter syndrome, libraries may be able to assist campus offices working with student groups such as first-generation students. As our study illustrates, first-generation students are a complex and multidimensional group with a multitude of anxieties, perceptions, and strategies for successful matriculation into campus life. As we will show through our data, there are trends that librarians can use to address culturally specific needs for this particular cohort.

\section{Literature Review}

This project takes a cue from Lisa Hussey's chapter on the potential connections for Bourdieu's Habitus within the LIS field (Hussey, 2010). In this work, Hussey outlines the areas for the usage of Habitus and points the direction for future work. Hussey's essay sits within a collection of papers that frames one of the important divides in Critical Librarianship as the interpretation of the notion of the critical is debated along the lines of philosophical framing on the one hand and social engagement and action on the other (Leckie, Given, and Buschman, 2010). As with many recent studies into Critical Librarianship, our project aims for praxis as we utilize the philosophical framework to inform a socially conscious project. As such, this project aligns well with the literature of Bourdieu himself whose major work sits comfortably on the bookshelves of both humanists and social scientists.

Extant work into the complications surrounding the implementation and research areas available to librarians interested in highly theoretical projects such as Bill Crowley's work discussing the theory-practice divide has provided a helpful framework for the appropriateness of this approach (Crowley, 2005). Using Crowley's terminology, the practical usage of Bourdieu's Habitus would constitute a "useful theory," that is, a theory or construct that "reflect, to some degree, 'how things work' in real-world contexts (Crowley, 7, 2005)." The assumption with Crowley's differentiation between "useful theory" and others is precisely the distinction made above. Habitus provides a framework for questioning assumptions and finding a direct link to practice through the increased and multidimensional evidence found in a study (Crowley, 2005). In fact, as Julien Duval writes in the introduction to his paper on the heuristic usage of 
Bourdieu's theories, Bourdieu himself sought a level of praxis in all of his work and a reciprocal theory-practice justification. Digging, as he did, into the etymological roots of the term theory, Bourdieu sought to both fight against the strict positivism of empirical research and to ensure a meaningful research philosophy behind the essential questioning phase of research development (Duval, 2015). The goal of research within this construction is to see a holistic scope of immediately perceivable outcomes as well as more abstract social meanings. We will return to the use of theory as a heuristic tool below as we explore the use within the LIS context, but the etymological constructions of the word help to conceptualize some of the rudimentary purposes of this type of project and highlight elements of the divide between practice and theory. As explored above, the main use of theory within our context is to provide a framework for questioning one's motivation in research and to orient goals within a larger context than a causal relationship analysis often allows. Within education and higher-education literature, there is an equally vast utilization of Bourdieu to assess the connection between aspects of class, cultural norms, linguistic differences, and various outcomes relating to student and educator success. Similarly, Dumas and Ward looked to understand the connection between cultural capital and college retention but did not find a clear correlation between appreciation of culture and student success (Dumas and Ward, 2009). Tramonte and Willms conducted a similar experiment, but looking at international students and international success data and found that there was a correlation between cultural capital indicators and success, but argue that static cultural capital that is, the capital as defined by the subjects' parents and authorities did not indicate success as conclusively as dynamic cultural capital which indicates the subjects' ability to align with peers and to establish a sense of fit (Dumas and Ward, 2009). Additionally, as the use of Bourdieu continues to find adherents across the disciplinary divides, some researchers have called into question its utility. Citing issues of misapplied or incorrect usage in various studies, some researchers have advocated against a strict adherence to formulaic elements of Habitus or in developing an overly proscribed study using its precepts (Nash, 1999; King, 2000; Reay, 2004; Silva, 2016). We will return to the notion of the use of theory throughout this brief and necessarily incomplete review, but it is important to understand the philosophical underpinnings of this research as it frames our approach, our goals, and our justification of methods.

Logan and Pickard's 2012 ethnographic study of first-generation students exemplifies both the positive results of focused and deep social science approaches to developing a user profile, but also falls into something of a reductive and proscribed model in order to do so. Tellingly, this was also Bourdieu's frustration with Anthropology as a discipline. Bourdieu's landmark study Outline of a theory of practice (Bourdieu, 1977) stems first from his fieldwork during his time teaching in the then French colony of Algeria studying cultural signifiers in Kabylia first published as Les Algerians in 1958 and later reworked and analyzed as Esquisse d'une théorie de la pratique in 1972. Bourdieu addresses the central concern with traditional Anthropology on the first page of his work with a discussion of "The objective limits of 
objectivism." In this section, Bourdieu discusses the work of Charles Bally and the inherent bias of observation. It is made clear, this discussion, that the researcher's own background (later explained as Habitus) overburdens the observed and the choices of representation and significance of behavior are determined by the lens of the researcher. In Bourdieu's words, "each agent, wittingly or unwittingly, willy nilly, is a producer and reproducer of objective meaning (79)." Biases unacknowledged, therefore, create or rather invent notable differences. These central elements problematize the ethnographic approach by instilling an impassable barrier of difference and by subjugating the subject as the observed other which, in a Foucauldian framework, is the purest expression of power. The ethnographic approach, while useful, does perpetuate certain problematic elements of essentialism through the selection and categorization of students and the conclusions drawn about their behaviors. It must be acknowledged, however, that hurdles of essentialism and generalization are extremely difficult to clear and are central problems of the social sciences and not the fault of individual authors.

There is no shortage of studies seeking to assess the value of libraries to the student experience and, importantly, to student retention. Soria, Peterson, Fransen, and Nackerud found that library engagement correlated to higher scores in the areas of critical and analytical thinking, written communication, and reading comprehension than their control group (Soria, Peterson, Fransen, and Nackerud, 2017). Additionally, Murray, Ireland, and Hackathorn found a strong correlation between library use and freshman and sophomore student retention (Murray, Ireland, and Hackathon, 2016). Thorpe, Lukes, Bever, and He found a strong relationship between the increased use of library service points and materials and an overall increase in student GPA (Thorpe, Lukes, and Bever, 2016). Similarly, Gaha, Hinnefeld, and Pellegrino were able to connect information literacy efforts with student success and a positive curve in student GPA (Gaha, Hinnefeld, and Pellegrino, 2018). While the majority of these studies stem from a direct assessment of instruction or service intervention, other studies have looked at library impact on student success from a larger perspective focusing on a more holistic argument from the position of leadership as opposed to direct practice. For example, Hess, Greer, Lombardo, and Lim discuss the value of partnership on the support of students and their success (Hess, Greer, and Lombardo, 2015). Miller also identifies the library as a third space (another vast literature too deep to plumb for this review) and discusses the positive impact on the student experience (Miller, 2013). Additionally, Gabby Haddow found a correlation between the increased rate of library online materials and a steady retention rate on campus (Haddow, 2013). All of the above articles represent a sample of a vast and still-growing literature focused on the library's role in student success and the need to publicize these successes to demonstrate the value of libraries in an ever-increasingly resource-competitive campus environment. This study frames some of the areas of disagreement with the current models of research into library use but does serve to standardize elements of library use and college normative behavior. 
In this study, however, the authors will not directly connect college normative behaviors to the likelihood of attaining academic or professional success. Rather, we rely on the framework of culturally responsive, or reflective, teaching to create a holistic approach to educational engagement that compliments Habitus and centers the need to address the complex cultural experiences and backgrounds of students. Culturally reflective teaching is "A pedagogy that acknowledges, responds to, and celebrates fundamental cultures that offers full, equitable access to education for students from all cultures" (Ladson-Billings, 1994). The instructor acts as a facilitator to create a student-centered learning environment that affirms students' strengths, insights, and experiences. Every student is unique, and they bring their own experiences and areas of expertise to a classroom, which we, as teachers, are completely unaware of until we engage with them individually. Additionally, as Elizabeth Foster discusses in her well sourced literature review and article, there is a dispositional and institutional understanding that diversity of experience is an asset, not a hindrance to education (2018). Foster advocates for a library-instruction model based on purposeful preparation, inclusive instructional design, personal accountability, reflection, and assessment. As with many articles discussing pedagogical models within the library instruction landscape, there is a high degree of theoretical linking and reliance on other literatures to note specific impact. As librarians will know, the difficulty in obtaining reliable, consistent, and statistically meaningful data is great given the lack of opportunity for secluding a control group or in acknowledging all variables.

As a linking practice and literature, Critical pedagogy and librarianship tie many of these notions together and serve as an important philosophical keystone in the development of our survey and the analysis of our data. To Smith, educating students should go "beyond providing access to information" and encourage them to also think critically about how information is created and disseminated (Smith, 2013). Critical librarianship, a subset of this philosophy, "places librarianship within a critical theorist framework that is epistemological, self-reflective, and activist in nature" (Garcia 2015). The practice of critical librarianship requires library professionals to examine student perceptions regarding our spaces and resources, the benefit of engaging with librarians, and their own information-seeking habits. It can also be an approach to thinking critically about the expectations and assumptions librarians may have regarding college normative students. The key components of critical pedagogy are also related to social constructivism, which recognizes that students do not process information passively.

Tewell (2015) and Elmborg (2012) stress the importance of librarians moving away from teaching information literacy as a mechanism to build skills and competencies to help students meet their academic benchmarks and general education requirements. The goal of attaining academic success, while important to consider, should not be the sole outcome for teaching information literacy to students. Critical information literacy can encourage self-reflection and consciousness of the "inherent privileging of information" (Doherty, 2008). One of the benefits of this work is the potential to develop learning spaces and communities that enable students to 
identify areas of personal interest for further discovery, and for librarians to reconsider or shift the areas of this work that fail to encourage critical thinking. It is important to recognize the lack of literature on the results of using critical information literacy in library instruction programs, but the impact of using critical information literacy can help librarians focus less on building skills and competencies regarding research to building other important components like selfawareness and community building (Tewell, 2015).

Our framework and model for engagement is influenced by discourse on the multifaceted experiences of college normative students in academic libraries, and the understanding that these experiences can be, like Habitus, rooted in cultural and personal attitudes and access to information. Research addressing college readiness comes from different areas of educational, sociological, and psychological research each with their own expansive literature and areas of debate. As with many researchers working with the notions of Habitus as a theoretical framework, there are elements of practice that cannot be adapted to the individual experiment. Reasons for these exclusions are multifold, but in our case, for example, elements of the Bourdieusian construction go beyond our scope and more importantly seek to correct behaviors in a way that we do not find appropriate. This sort of corrective work is evident in some recent usages of Habitus such as Michael Gaddis' 2012 article in which he explores the inherent inequalities of the American education system. Within this article, however, Gaddis is exploring attitudinal elements associated with the acquisition of cultural capital; an issue we address in this work, but from a different perspective on the value of this acquisition (Gaddis, 2012).

\section{Method}

A mixed-methods survey containing fourteen questions was distributed to a targeted group of first-generation students enrolled in the Summer Transition Program through the Academic Achievement Program, students from the Academic Achievement Program's transition course, and self-identified students from the College of Education at the University of Maryland, College Park beginning in the fall semester of 2018 and continuing through the spring semester of 20193. The survey was composed of three distinct sections covering student demographic information, goals at the University of Maryland, an academic profile including current anxieties pertaining to their transition to the university, and a profile of their familiarity with library services and terminology. The survey was composed of seven quantitative questions and seven qualitative questions and was developed and distributed using RedCap. Following data collection, we analyzed the qualitative data by coding responses and identifying narrative and phenomenological trend clusters from the sample group. Quantitative data was also analyzed to note internal trends and to build a profile of the group sampled.

\footnotetext{
3 Special thanks to Chanelle Pickens and Rachel Eck for their contributions to an earlier version of the worksheet, which was created in 2016.
} 
As discussed above, there is no exact method or template for applying Bourdieu's work into other fields. It is also important to note that Habitus is a sociological observation and has, like all theory, problems if applied as a blanket heuristic. In fact, Bourdieu's tool for data collection within the theoretical apparatus of Habitus is overly deterministic and prescriptive and unsuitable for modern studies. It is the spirit and the general method that we sought to apply. Through Bourdieu's questionnaire he seeks to determine a multidimensional model of his subjects based on direct and indirect observation and a battery of pertinent questions to determine a portrait of his participants that delves deeper into their cultural assumptions, aspirations, and preferences in order to more fully explain their lived experience within their regular field of practice (Bourdieu, 1984). As such we utilized Habitus as a way of investigating respondent assumptions, anxieties, and beliefs as a way of understanding how internalized codes affect students as they matriculate into the university system and culture. Like Bourdieu, we asked questions that established a set code of practice and sought responses that spoke to these codes. For example, we asked respondents a mixture of open-ended and multiple-selection questions asking them to describe their personal and educational values. Unlike Bourdieu, our questions were not assessing cultural indicators, but indicators pointing to specific concerns of students growing up with fewer expectations of collegiate life, the established codes of collegiate success, and the languages of academia. As such we coded the qualitative data determining the rates of language indicating their desired communicated values. These values were determined to fall into three primary categories: directed skills (i.e. wishing to direct the reader to their work-style exemplified by terms like "meticulous," or "attentive"), performative language (i.e. seeking to speak to a perceived desire on the part of the reader exemplified by terms like "hardworking," or "eager"), or indicator of interpersonal skills (demonstrating values that speak to their projected personality and desire to fit in exemplified by terms like "helpful," or "caring"). We then coupled these responses with a second set of coded qualitative data from the survey which asked respondents about their concerns as they matriculate into the university setting as first-generation students. As with Bourdieu's aim with his studies on Habitus and specified populations, our core aim was to explicate the whole student and develop an understanding of how their assumptions about successful cultural practice were informed by their unique backgrounds as first-generation students. In other words, our survey questions brought out and focused on issues central to a perceived understanding of the cultural codes needed for successful practice in a field in which these students are less familiar due to their background and inherent capital.

\section{Results}

The data presented below provide three clusters of information that make up a Habitusinspired library profile of the students surveyed. Through the data, we can understand selected demographic information, educational and dispositional values, and information about library use and experience. 
The research team received forty-two complete responses $(n=42)$ during the length of the data collection period. The average age of the respondents was 19.60 years old with seven unique values entered giving a range from 18-24. (Figure 1).

\section{Figure 1}

Age of Respondents

\begin{tabular}{|c|c|c|c|c|c|c|c|c|c|c|c|c|c|c|}
\hline \multirow{2}{*}{$\begin{array}{l}\text { Total } \\
\text { Count } \\
\text { (N) }\end{array}$} & \multirow[b]{2}{*}{ Missing } & \multirow[b]{2}{*}{ Unique } & \multirow[b]{2}{*}{ Min } & \multirow[b]{2}{*}{$\operatorname{Max}$} & \multirow[b]{2}{*}{ Mean } & \multirow[b]{2}{*}{ StDev } & \multirow[b]{2}{*}{ Sum } & \multicolumn{7}{|c|}{ Percentile } \\
\hline & & & & & & & & 0.05 & 0.10 & 0.25 & $\begin{array}{c}\mathbf{0 . 5 0} \\
\text { Median }\end{array}$ & 0.75 & 0.90 & 0.95 \\
\hline 42 & $0(0.096)$ & 7 & 18.00 & 24.00 & 19.60 & 1.53 & 823.00 & 18.00 & 18.00 & 19.00 & 19.00 & 20.00 & 21.90 & 22.95 \\
\hline
\end{tabular}

Lowest values: $18,18,18,18,18$

Highest values: $22,22,23,24,24$

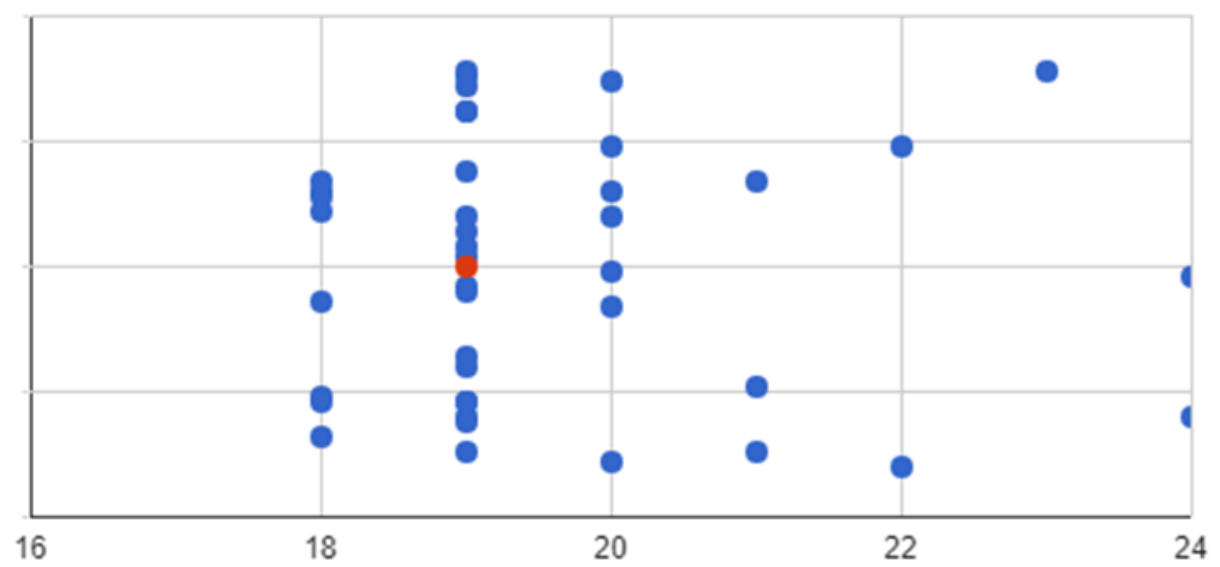

Within these forty-two responses, 32 (76.19\%) indicated their first language as English, 8 (19.04\%) indicated their first language as Spanish, 1 (2.38\%) indicated their first language as Arabic, and 1 reported a fully bilingual home (English and Spanish). The majority of the respondents $(30,71.6 \%)$ did not attend a community college or another university (12 or $28.6 \%$ responded yes).

The respondents indicated their reasons for choosing the school at which our study took place. The survey provided a free response field and therefore allowed respondents to provide multiple reasons within their answers. Their responses were then coded and clustered into thematic trends. Among the forty-two respondents, therefore, we gathered sixty-one unique reasons for choosing our campus. The breakdown of these responses is as follows (Table 1). 


\section{Table 1}

Reason for Choosing University of Maryland

\begin{tabular}{lc}
\hline \multicolumn{1}{c}{ Reason } & Rate \\
\hline College reputation & $24(39.34 \%)$ \\
Close to home & $16(26.23 \%)$ \\
Instate tuition and tuition cost & $9(14.75 \%)$ \\
First-generation opportunity & $1(1.63 \%)$ \\
Personal opportunity & $7(11.47 \%)$ \\
Diversity & $2(3.27 \%)$ \\
Null & $1(1.63 \%)$ \\
\hline
\end{tabular}

Students were additionally asked about their intention to join a club or other university group. Respondents indicated a range of answers from o clubs or groups to interest in joining up to 7 clubs or groups. Of these responses, however, data indicates some interesting dispersal among club types. Respondents provided fifty-nine answers total. When specific clubs were mentioned or specific club categories indicated, they fell into one of the following classifications at the rates indicated in Table 2.

\section{Table 2}

Club and Campus Identity Information

\begin{tabular}{llcc}
\hline \multicolumn{1}{c}{ Club Type } & \multicolumn{1}{c}{ Example } & $\begin{array}{l}\text { Number of } \\
\text { Responses }\end{array}$ & Rate \\
\hline Academic & $\begin{array}{l}\text { Honors societies and other } \\
\text { discipline-specific clubs }\end{array}$ & 7 & $\mathbf{1 1 . 8 6 \%}$ \\
Cultural & $\begin{array}{l}\text { Music clubs or other arts-based } \\
\text { clubs }\end{array}$ & 6 & $\mathbf{1 0 \%}$ \\
Athletic & $\begin{array}{l}\text { Club or intramural sports or other } \\
\text { recreational clubs }\end{array}$ & 8 & $13.5 \%$
\end{tabular}




$\begin{array}{llcc}\text { Greek life } & \text { Fraternities or sororities } & 1 & 1.69 \% \\ \text { Philanthropic } & \begin{array}{l}\text { Mentoring, volunteering, or other } \\ \text { community assistance clubs }\end{array} & 7 & 11.86 \% \\ \begin{array}{l}\text { Ethnicity-based academic } \\ \text { societies }\end{array} & \begin{array}{l}\text { Society of Hispanic Profession } \\ \text { Engineers }\end{array} & 3 & 5 \% \\ \begin{array}{l}\text { Diversity and advocacy } \\ \text { societies }\end{array} & \text { Muslim Student Association } & \\ & & 7 & \\ \text { Not interested in clubs } & \begin{array}{l}\text { Indicated no interest in university } \\ \text { clubs or societies }\end{array} & 15 & \mathbf{2 5 \%} \\ \text { Yes, unspecified } & \text { Interested in clubs, but nothing } & 5 & 8 \% \\ & \text { specified } & & \end{array}$

Taken in conjunction with the data presented above, of the most important aspects of our data collection was to understand how the students choose to represent themselves, their anxieties about starting classes at the university, and to understand their current goals and ambitions. Students were asked to provide three adjectives they would use to describe themselves to their professors. Within these results, the research team identified three major trend areas. Responses were coded to note these trends and clustered to create 118 responses. The research team defined the trend areas as: aptitudinal or skills-based language; performative or aspirational language; interpersonal or attitudinal language (Table 3 and Figures 2, 3, and 4).

\section{Table 3}

Index of Personal Identity Language

\begin{tabular}{llcc}
\hline \multicolumn{1}{c}{ Language Cluster } & \multicolumn{1}{c}{ Indicators } & $\begin{array}{c}\text { Example from } \\
\text { data }\end{array}$ & $\begin{array}{c}\text { Rate of } \\
\text { occurrence }\end{array}$ \\
\hline $\begin{array}{l}\text { Aptitudinal or skills-based } \\
\text { language }\end{array}$ & $\begin{array}{l}\text { Indicating work style or } \\
\text { ability }\end{array}$ & "detail oriented" & $13(11 \%)$ \\
$\begin{array}{l}\text { Performative or aspirational } \\
\text { language }\end{array}$ & $\begin{array}{l}\text { Indicating mentality or } \\
\text { values }\end{array}$ & "hard working” & $45(38 \%)$ \\
$\begin{array}{l}\text { Interpersonal or attitudinal } \\
\text { language }\end{array}$ & $\begin{array}{l}\text { Indicating aspects of } \\
\text { personality }\end{array}$ & "caring" & 60 (50.8\%) \\
\hline
\end{tabular}




\section{Figure 2}

Aptitudinal or Skills-Based Language Frequency

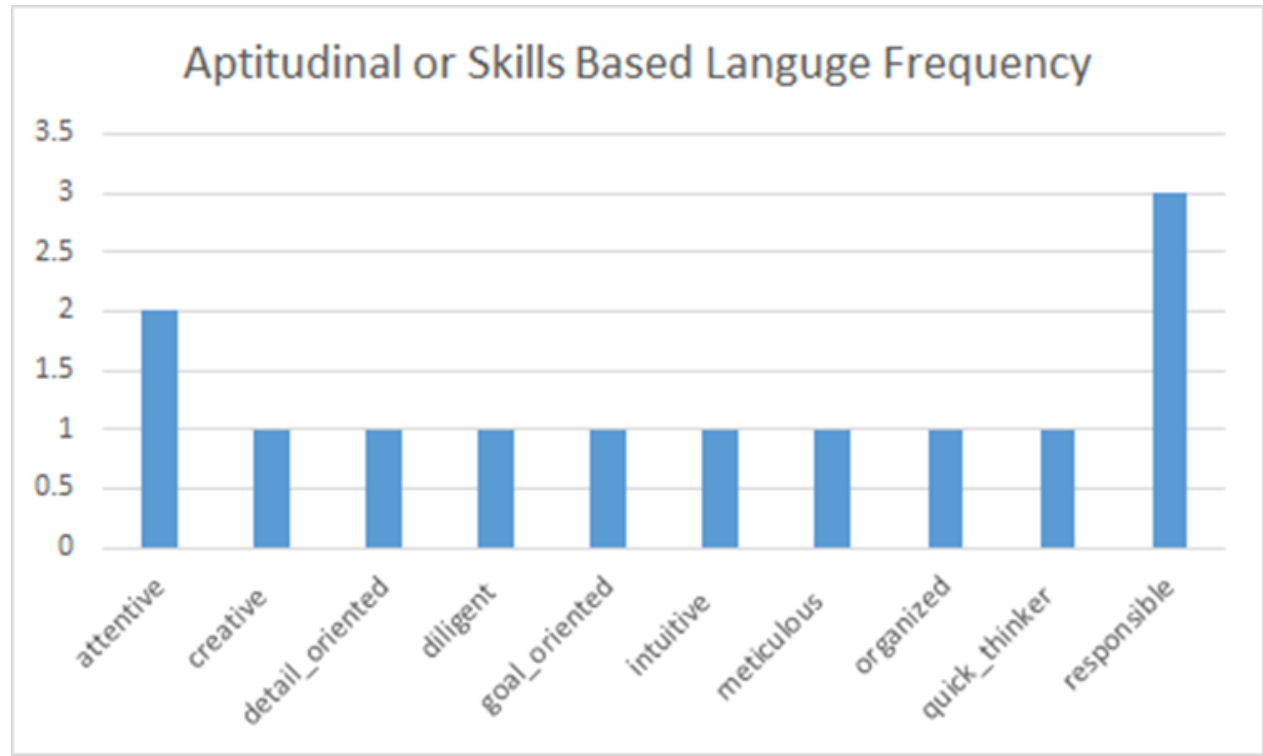

\section{Figure 3}

Performative or Aspirational Language Frequency

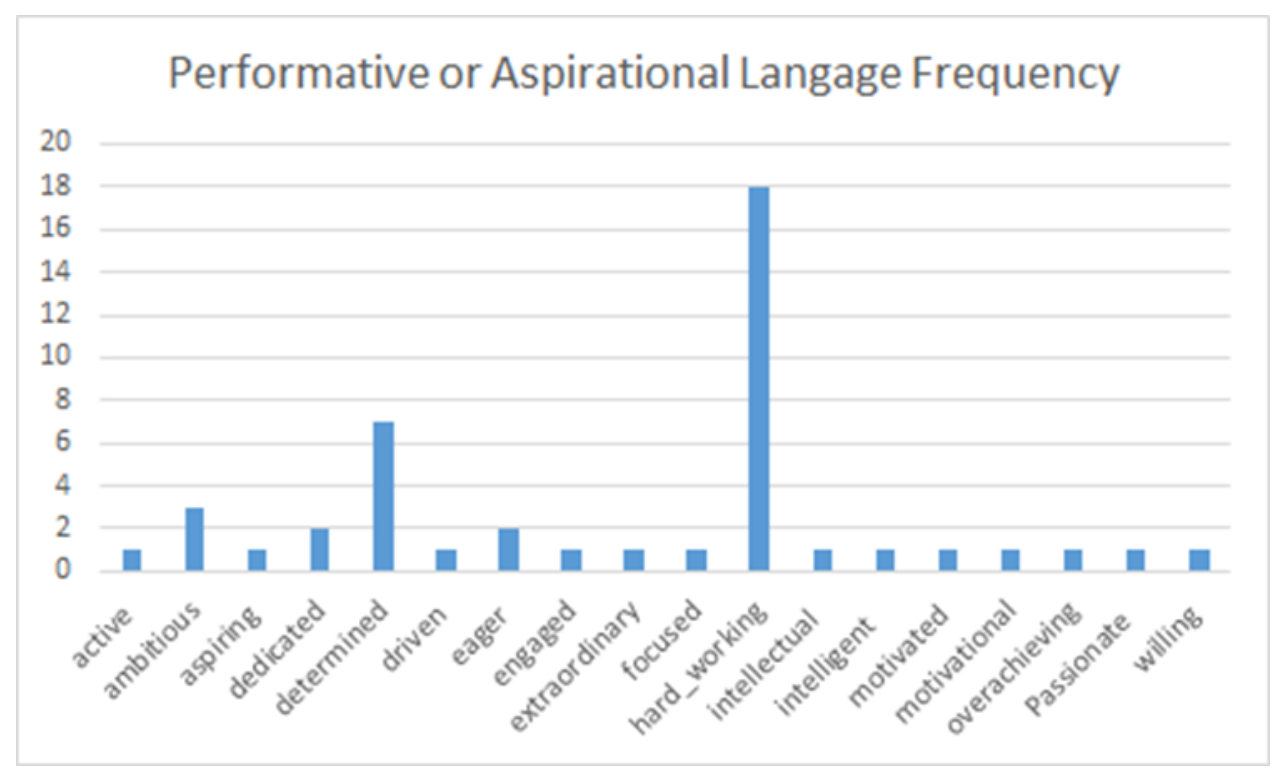




\section{Figure 4}

Interpersonal or Attitudinal Language Frequency

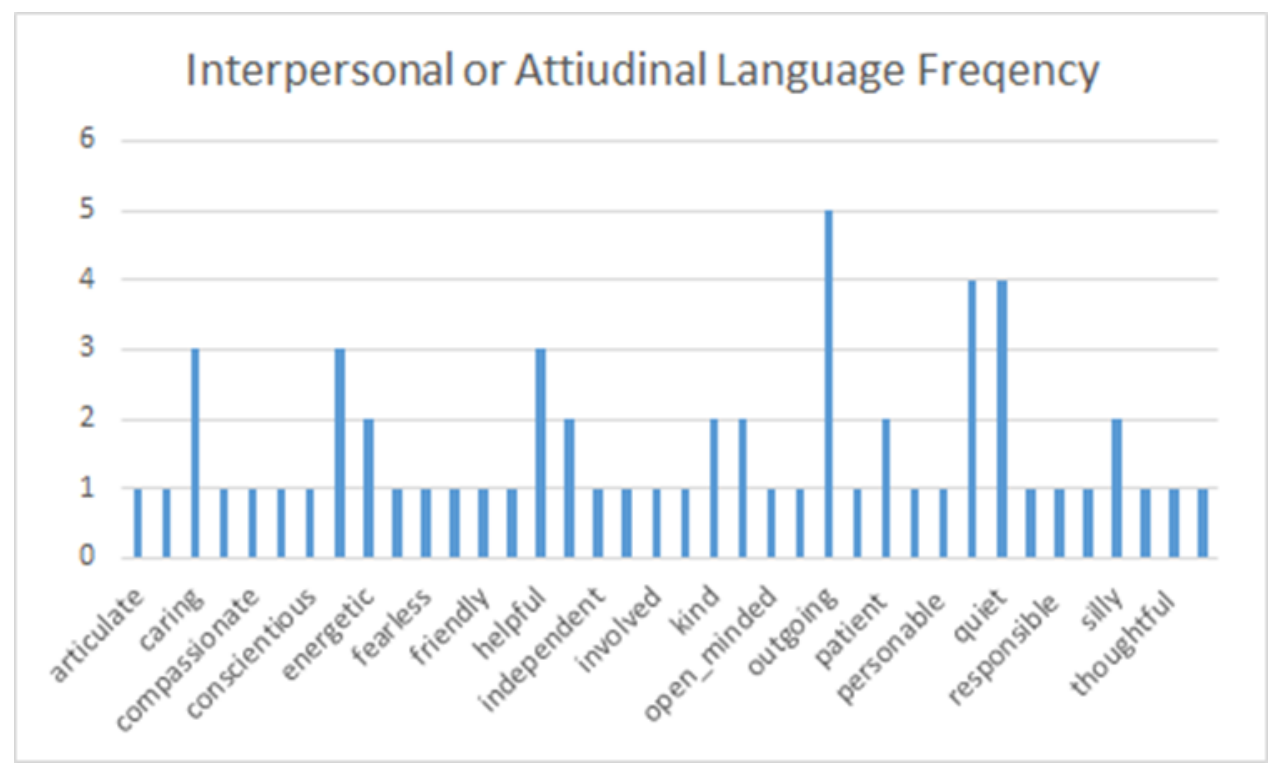

Our survey also looked to expand the view of what students were willing to tell us about their fears and anxieties regarding their transition to the University of Maryland. As indicated in our data, $71 \%$ (30 responses) of the students surveyed were not entering the university as transfer students from either a community college or another university. This is an important framing metric to understand the anxieties and concerns which reflect those of incoming firstyear students from a predominantly first-generation background.

The students reported anxieties in seven discernable categories. These responses are grouped by the general sentiment and pervading anxiety present in the response. There was a total of 78 responses stemming from the participants with some students providing multiple distinct response categories as indicated in Table 4 . 


\section{Table 4}

Index of Anxieties

\begin{tabular}{|c|c|c|c|}
\hline $\begin{array}{l}\text { Response } \\
\text { Category }\end{array}$ & Characteristic & Example & $\begin{array}{c}\text { Rate of } \\
\text { occurrence }\end{array}$ \\
\hline $\begin{array}{l}\text { Time } \\
\text { management }\end{array}$ & $\begin{array}{l}\text { Anxiety involving fear of not } \\
\text { being able to keep up with } \\
\text { course material }\end{array}$ & $\begin{array}{l}\text { "Not turning in assignments } \\
\text { on time" }\end{array}$ & $13(16.6 \%)$ \\
\hline $\begin{array}{l}\text { Academic } \\
\text { concerns }\end{array}$ & $\begin{array}{l}\text { Feelings of inadequacy, } \\
\text { anxiety about difficulty, or } \\
\text { concerns about volume of } \\
\text { work }\end{array}$ & $\begin{array}{l}\text { "Feel as though many } \\
\text { people are smarter than me } \\
\text { and have a grasp on how to } \\
\text { be a college student" }\end{array}$ & $25(32 \%)$ \\
\hline $\begin{array}{l}\text { Lack of } \\
\text { resources }\end{array}$ & $\begin{array}{l}\text { Concern that there are not } \\
\text { enough help centers across } \\
\text { campus or not being able to } \\
\text { access requisite resources }\end{array}$ & $\begin{array}{l}\text { "Not having enough } \\
\text { resources inside and } \\
\text { outside of school" }\end{array}$ & $4(5 \%)$ \\
\hline $\begin{array}{l}\text { Social } \\
\text { concerns }\end{array}$ & $\begin{array}{l}\text { Anxieties around not } \\
\text { finding a social or academic } \\
\text { fit on campus }\end{array}$ & $\begin{array}{l}\text { "Finding where I fit in and } \\
\text { making friends" }\end{array}$ & $23(29 \%)$ \\
\hline Size of UMD & $\begin{array}{l}\text { Concern over the physical } \\
\text { size of the campus }\end{array}$ & $\begin{array}{c}\text { "Not being able to find the } \\
\text { buildings, classes, resources } \\
\text { I need" }\end{array}$ & $4(5 \%)$ \\
\hline $\begin{array}{l}\text { Financial } \\
\text { stress }\end{array}$ & $\begin{array}{l}\text { Fear of academic failure due } \\
\text { to lack of monetary } \\
\text { resources and associated } \\
\text { complications }\end{array}$ & $\begin{array}{c}\text { "Not being able to graduate } \\
\text { due to financial issues" }\end{array}$ & $6(7.6 \%)$ \\
\hline $\begin{array}{l}\text { General } \\
\text { anxiety }\end{array}$ & $\begin{array}{l}\text { Anxieties that relate to more } \\
\text { general concerns stemming, } \\
\text { perhaps, from medical or } \\
\text { other complications }\end{array}$ & $\begin{array}{l}\text { "Not being happy with my } \\
\text { life after I graduate" }\end{array}$ & $3(3.8 \%)$ \\
\hline
\end{tabular}


Unlike with the above adjective analysis, the concerns were reported at a more individualized level with far fewer repeated phrases. Within each coded category, however, noticeable and interesting trends - albeit at a lower recurrence rate- provide areas for further analysis.

Following this self-indicated list, participants were asked to select five dispositional verbs that indicate the values that are most important to them at this stage in their education. As illustrated below, the results were fairly evenly distributed with the choice "making good grades (33, 78\%)" only slightly edging out "making my parents proud (30, 71\%)," and "learning more about myself $(29,69 \%)$," for the most responses. Curiously, no respondent selected the choice of "other" from the list. The majority choices align with the personal sketch of anxieties provided by the student in that they indicate an overall concern with academic performance as well as personal and social roles within the university (Figure 5).

\section{Figure 5}

\section{Educational Values}

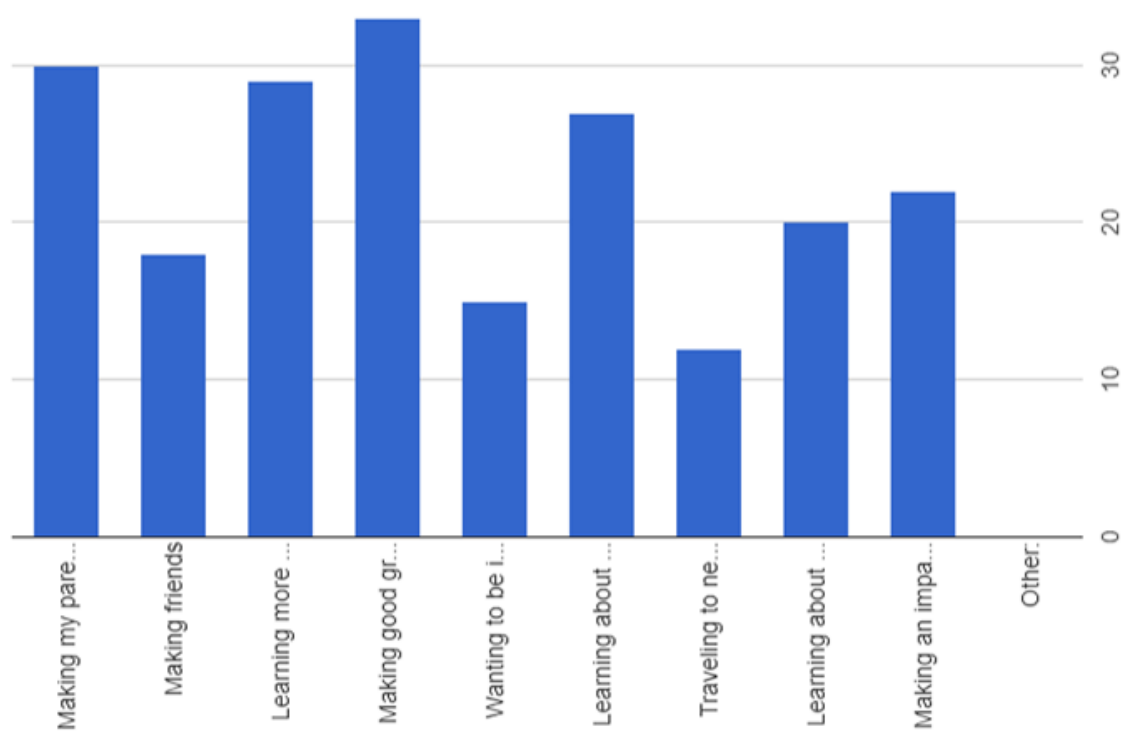

Counts/frequency: Making my parents proud (30, 71.496), Making friends (18, 42.996), Learning more about myself $(29,69.096)$, Making good grades $(33,78.696)$, Wanting to be intellectually challenged $(15,35.7 \%)$, Learning about new and interesting things $(27,64.3 \%)$, Traveling to new places $(12,28.6 \%)$, Learning about job/career opportunities (20, 47.696), Making an impact in my community $(22,52.496)$, Other: $(0,0.096)$

Following our questions aimed at developing a personal portrait of the students, we asked a series of questions to address their library use as both high school students and as early 
college students in order to understand their level of comfort with spaces, services, and terminology in order to enhance the portrait of the personal profile with ways to better serve first generation students. To achieve this, we first sought to understand the average frequency of library usage of this group as high school students. Participants were given a range of answers from which to select that provides a generalization that characterized their use. The choices of responses to the question "How often would you say you used your high school library?" were (Table 5).

\section{Table 5}

High School Library Use

\begin{tabular}{lc}
\hline \multicolumn{1}{c}{ Response } & Rate \\
\hline My School Didn't have a library & 1 \\
Never Used it & $5(11.9 \%)$ \\
1-2 times per year & $12(28.6 \%)$ \\
About once per month & $9(21 \%)$ \\
More than once per month & $7(19 \%)$ \\
At least once per week & $7(16.7 \%)$ \\
\hline
\end{tabular}

Of particular interest to the development of a first-generation student portrait is their familiarity with the terms, people, and services offered by the University of Maryland Libraries. The researchers compiled a list of cross-departmental terms that are likely to be used in the first or second year of the students' university career. Students were not limited in how many items they could select. As will be discussed below, some of the terms may have caused some confusion as they have multiple meanings, and it is not clear if the students understood the term in a library context or with a different meaning (e.g., "scholarship"). What is of particular interest is what terms were not unfamiliar to the student group. Terms such as "journal article," "peer review," "call number," and "citation" received a low number of clicks, where services and people received a high number (Table 6 and Figure 6). The top terms that students were most unfamiliar with were: 


\section{Table 6}

Library Term Familiarity

\begin{tabular}{lc}
\hline \multicolumn{1}{c}{ Unfamiliar Term } & Rate \\
\hline Makerspace & $29(69 \%)$ \\
Interlibrary loan & $24(57 \%)$ \\
Commons & 19 \\
Subject librarian & $(42.56 \%)$ \\
Reference Manager & $19(42.5 \%)$ \\
Archivist & $13(31 \%)$ \\
Library instruction & $13(31 \%)$ \\
\hline
\end{tabular}

\section{Figure 6}

Library terms familiarity

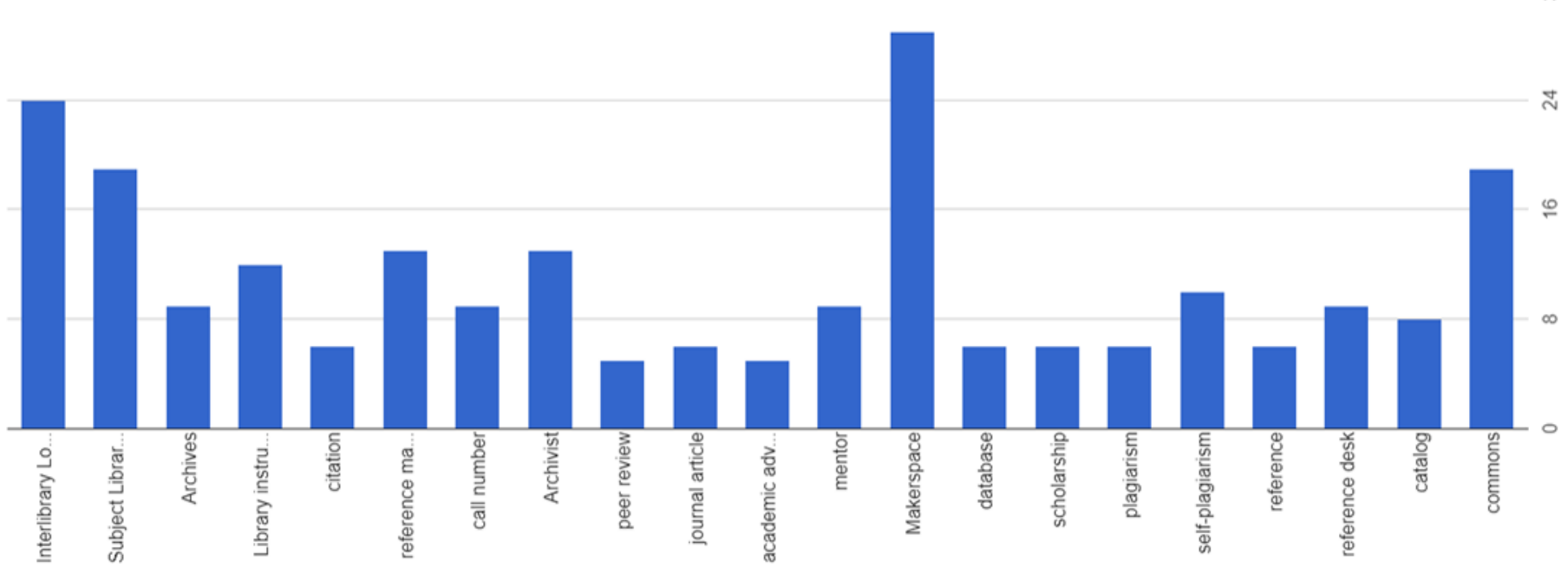

The penultimate question in our data collection and first-generation student profile asked for what activities does the student currently use the library? 
The vast majority (38 or 90.5\%) of the students surveyed indicated that they use the library as "a place to study/complete homework." The next highest response (23 or 55\%) were students who use the library for "group projects" and students who use the library to "use the internet to complete coursework" having only one fewer response (22 or 52\%). The remaining responses were chosen at considerably lower rates. The response "use technology," represented 14 students (33\%), "pick up a snack" represented 11 students (26\%), "relax/meditate" represented 9 students (21\%), and “I don't use the library" represented only 2 students (5\%).

Finally, we allowed the respondents to enter final comments and things that they would like the library to know about their experience with the libraries and their transition to the university. We received 12 unique responses. With only one exception (regarding service outreach), the responses were too individualized to thematize or code in a meaningful way. That said, however, each response is interesting and helps to complete the portrait we are hoping to develop from this particular sample group. Below are the student responses which have been edited only to remove personal information. Spelling, grammar, and content have not been corrected or altered in any other way. Any omission will be represented with the following notation: [omitted for privacy].

- I know the library has many resources, but a lot is unknown to students. I once paid for an expensive program for a class that was provided for free on the library computers. If $i$ had known the computers already had this resource, I could have saved a lot of money.

- would like to know more about resources libraries offer, outside help i can bring home (i.e., wifi, laptops)

- I think transfer students have the hardest time making friends, and keeping them outside of just the 'class friend whose friendship with you ends

- First year can be very hard for students of color environment and representation wise

- I know there are multiple libraries in campus, but I do not know them all or where they are specifically. And I guess it would be helpful to know if one library leaned more towards some subjects then other libraries did because I know they do not all have the same resources available.

- It was great to have a professor/faculty member to really care and willing to answer my questions. My advisor at the beginning was [omitted for privacy] and has moved to another department. She was very sweet and resourceful. She answered all of my questions in a timely manner and was genuine when it came to me stopping by her office. I'm uncomfortable with change and she definitely helped me transition smoother.

- I really enjoy the library!!

- I really wish there were more quiet places in campus (that were enforced!) Even the 'quiet' floors in McKeldin are often really noisy and as a student I feel uncomfortable trying to ask my peers to be quiet when I need to work. Many times, Hornbake is so loud I can't focus, or I can't find any place to sit in McKeldin to have a quiet place to study. 
- the elevator is really slow. there should be vending machines on every floor. I wish it was closer to stamp.

- The study carrels are the best part of the library

- I would request that technology should be lent out to the student for more time. As well that fees and charges shouldn't be difficult to request an appeal.

- Friendlier technology desk service

\section{Discussion}

Habitus provides a lens for seeking new information and seeing the data in a more complex and intersectional way. As researchers we are not Bourdsian, but we do believe that the insights of Bourdsian sociological frameworks align with an expanded understanding of a subject's background as it informs their current practice. Put into terms of this project, that a student's practice in the field of higher education is a dependent product of their background. Habitus can be deterministic to a fault, but as discussed above, our focus in this project and in our use of Habitus is to find the areas of cultural dominance and instances of performed as opposed to embodied cultural value in order to introduce concepts -in this instance college services and library terminology - in a way that reduces the mental effort in what is essentially the development of a new cultural vocabulary.

Through the data presented above, we can identify crucial elements and components which allow a Habitus lens to be applied to the interpretation. As a product of both survey design and student response, we see the students using language that reflects the three central elements of Capital through individual contribution and attribution adjectives, Fields through the language reflective of college norms, and Doxa through language focused on personal and performance-based expectations. Additionally, through the highly suggestive performative language, we see aspects of mimesis as relating to the perceived Doxa or expected performance norms. Put another way, the language we've interpreted as being performative can be seen as such when applying social context to the terms and placing them against the practice of others.

Through our question on self-definition and description, for example, we were asking the students to define their sense of self and their values with regard to their education experience. It was our hope that by allowing students the space to write-in their own responses, as opposed to providing a list of adjectives determined by us, that we would gain a more accurate and inclusive understanding of the students' voice. It is suggestive that such a high percentage of the responses from our sample group fell into the categories of interpersonal or performative language, and so few responses spoke to their student's perceived aptitude. These adjectives represent, in our construction, elements of their Capital which speak to their own perceived value that they are bringing to the university. These adjectives were framed within a question about how they would want to be perceived by their professors, and it is therefore additionally suggestive that these aspirational and performative terms speak to their interpersonal behaviors as opposed to their skills or aptitudes. There are a multitude of dimensions to explore within 
these responses, but most of these interpretations must, for the moment, remain speculative. Why would a student be concerned with being seen as "smiley" or "driven?" What can these terms tell us as educators? The terms chosen by the respondents indicate their projected notions of fit or of successful practice with the university context. Strictly speaking, for first-generation students, the world of higher education represents a new culture. Again, this is not to suggest an otherness or a value judgement, but elements of the university experience are new. This newness may be a difficult transition practice for some of these students. Codes, language, expectations, and levels of experience are different and are also connected to sexist and racist notions of normalized behaviors. Students must then tune their own expectations, knowledge, and experience to this new culture. That said, however, aspects of the respondent's race, socioeconomic background, previous experience with educators, their perceptions of the researchers, their confidence in the confidentiality of the survey, and a whole host of additional variables would paint a more complete picture, but as facets of their Capital the adjective clusters presented above can point towards an interesting conception of self and, as illustrated below, with their role within the perceived strictures of university codes.

Of central importance to our study, students reporting feelings of inadequacy are of high concern considering the risk of alienation and students feeling unable or unwilling to remain at the university. In the survey students indicated feelings of inadequacy, concern about resources, and anxiety about academic performance. As with the questions looking at the students' adjectives of self-presentation, we asked the respondents to identify aspects of university life that they are anxious about. As presented above, $32 \%$ of the concerns centered around academic anxiety and a fear of perceived inadequacy. This fear, while likely among most first-year undergraduate students, indicates an area of discrepancy, perhaps, between their own conception of their Capital and their understanding of successful practice within this specified Field. Because of the unique backgrounds of each student, we should not generalize to the point of essentialism, but the combination of the self-description adjectives and the anxiety listings give us an understanding of the students' Cultural Capital and their perceptions of the Doxa or rules of practice within the university Field by providing both a summary of the traits they believe they will perform successfully, and a summary of their anxieties about the gap. Within our Habitus framework, we can understand both of these constructions as indicative of their embedded perceptions of the university experience emanating from their particular cultural experience. In other words, how these students have developed the limits, rules, dispositions, and practices stems from their previous knowledge. The important founding concept of this study is that because these students are first-generation, their previous knowledge may differ from college-normative students in very particular ways. Terminology reflective of college experience may be more a part of the college-normative student's early and secondary education experience, students may spend more time in detailed conversations with family members regarding college, and importantly students may enter the college campus with an enhanced understanding of the services and support to be found on a college campus. As indicated 
through our responses, these sample first-generation students worried about finding college support services, about knowing the terms and codes of university life, and about finding their fit. It is important to remember; these students were admitted to the university based on their credentials like any college-normative student. They belong on the campus, but elements of the language and practice have led to a feeling of alienation and a fear of inadequacy.

Our findings also indicate additional stressors felt by our sample group. While the firstgeneration students surveyed indicated normal concerns such as time management, all of the responses relate to other concerns such as anxiety related transition as discussed by Schlossberg and others. These anxiety indicators are evident through statements expressing fear about "not being able to keep up with the schoolwork" or related responses regarding anxiety about finding balance in their personal lives. These responses indicate a significant but known change in the students' life and represent both a change in status and a reliance on previous experience (Schlossberg, 1981). Through these responses, we can interpret anxiety surrounding these elements due to the insecurity about both the role change and how well their previous experience prepared them for the new experience. Additionally, our respondents discuss financial concerns including the fear of "not being able to graduate due to financial issues." Additional responses included two separate mentions of concerns regarding working and being a full-time student. Finally, students noted anxiety about the size of the campus and the increased number of students in each class. Taken alone, this anxiety can be applied to many students regardless of background, but coupled with the responses regarding feelings of inadequacy, this response again indicates a fear of not being able to live up to peer and professor expectations. This is highlighted, perhaps, in the response noting discomfort with the thought of "not connecting with the professor." Taken all together, we see a fear of slipping through the cracks and not being able to successfully transition to the new experience.

\section{Conclusion}

Through this project, we have illustrated how the selective use of Pierre Bourdieu's Habitus can aid in the development of user profiles for student populations. Habitus is a very particular framework that intrinsically problematizes and complicates the overly simplistic models of ethnographic data collection. As discussed, Habitus is not without its own problematic components, and therefore we show how diverting from the more causal and essentialist elements help in our overall perception of the first-generation students we studied. ${ }^{4}$ Other methods and other philosophies are a welcome and useful addition to this study. Work on

\footnotetext{
4 Confusingly, the data regarding their status as a first-generation student was mixed with 25 indicating that they were the first in their family to attend university and 17 indicating that they were not the first in their family to attend university. Because the target population was selected based on their affiliation with first-generation programs and advising, the discrepancy is likely due to our lack of clarity in the phrasing of the question and the lack of granularity in the choices available for answers. In other words, we should have allowed students to select a wider range of answers that indicated that their parents attended some college, their siblings have attended or are attending college, or other variants which would allow more complicated and accurate answers.
} 
transfer student populations by our colleagues in the Office of Transfer and Off-Campus Student Life, for example, demonstrate similar robust findings, but utilize work by educational theorists such as Schlossberg mentioned above. 5 Our study found that University of Maryland firstgeneration students bring with them a multitude of perceptions and strategies for successful matriculation into campus life. ${ }^{6}$ Interestingly, these perceptions and their associated anxieties do not necessarily map to successful normative practice.

The students surveyed displayed surprising gaps in their knowledge of library services. As indicated through the data, this may be due to inexperience or to linguistic differences in terms of services, people, or resources. This gap presents librarians with the clearest area for successful intervention, but, as our data suggests, careful and sensitive planning should be a part of this process. For example, our data clearly shows a sensitivity about campus fit and collegereadiness, so library programming should reflect an approach considering this issue. Finding the right language to ease feelings of imposter syndrome is important and therefore working with students to map their understandings, anxieties, and knowledge to the campus environment is a meaningful way to connect students to their education. In other words, it is clear through our data that the students we surveyed have the skills and knowledge for successful practice in the college field but may lack some of the specific knowledge and language to ease into the field without extra effort. Librarians are well positioned as educators to help bridge this gap in a non-punitive and culturally responsive way.

This is, of course, easier said than done. The researchers for this project encountered multiple challenges in the development of this study that are likely similar to the challenges other researchers have found while working with campus populations. One particular issue that slowed progress was the amount of buy-in from campus partners. This is a common issue for librarians. We worked closely with the office responsible for transitioning first-generation students who supported our goals but were often withholding data or student access. This could be a territorial issue as we were encroaching on their campus remit, but there is also likely something of a bias against librarians and seeing our role as more limited than it has become. As librarians in all fields of librarianship stretch beyond traditional roles, there may be partners or potential partners who may be less receptive to altering their conception of our role. As we continue to prove ourselves as educators, we can increasingly position ourselves as a studentsuccess-focused partner on campus, but we must increasingly utilize the critical education methods and theories stemming from adjacent fields and to develop our own "cultural language" for successful practice.

\footnotetext{
5 We are grateful for the help of Dr. Casey Maliszewski Lukszo. For more information on her work, please see her thesis: Maliszewski Lukszo, Casey Lynn. 2018. "The Triumphs and Tensions of Transfer Articulation: Investigating the Implementation of Maryland's Associate of Arts in Teaching Degree." Dissertation, 2018. doi:10.13016/M2DZ0352G.

${ }^{6}$ Due to the small sample size, we are not claiming that these findings are representative, but that they are interesting and are worth exploring in greater depth
} 
Our research indicates three distinct areas where libraries can directly help firstgeneration students:

1. Educators should embrace agility in the classroom. Listen carefully and analytically to student needs to avoid easy assumptions about first-generation students and their knowledge, skills, aptitude, and experiences. This will allow for more individualized and contextual library instruction and support services for this student population by avoiding a one-size-fits-all approach to first-generation students.

2. Understand the cultural codes and hidden language of your institution's policies and practices and develop ways to help students develop fluency in the cultural language in a non-prescriptive format.

3. Partner with offices focused on student success to more holistically understand and address student concerns, anxieties, and knowledge gaps alongside similarly studentfocused colleagues who have a valuable toolkit for working with students of all types.

4. Work to develop complex models of student needs stemming from collaboration, data collection, and observation.

5. Use these partnerships and collaborations to target and tailor resources, workshops, and other interactions to help students dealing with aspects of transition anxiety by connecting skills, services, and dispositions to familiar and previously developed ones in a team-based approach allowing different office to care for specific parts of the student's experience.

Introducing library services for first generation students is challenging, as our research indicates, due to the potential problem of essentializing through the distillation and codification of individual themes into problems to be solved through didactic instruction. Despite the best intentions of librarians, our limited access to students forces us to rely on generalizations. Our tools, too, are limited and force us to rely on methods and models which may reinforce, through the use of jargon or insider language, cultural and educational assumptions, and a lack of understanding about the core issues and knowledge gaps. Librarians often approach first generation and transfer student programs in similar ways and make similar assumptions about the problems inherent in these populations. Librarians want to solve these problems, of course, and we attempt to do so through the tools of our trade, but our research indicates that we may not have the adequate tools to fully address issues unique to these populations. Partnerships with first generation campus programs, student advisors, writing centers, and other student engagement offices may be of strategic importance as their skill set may align more fully with the student need. That said, however, librarians should be encouraged to design learning experiences that center on building resourceful thinkers through providing equitable access to resources. Feelings of inadequacy and cultural fit are areas librarians can lend our skills if we tailor our instruction lessons to be agile and allow for students to have an active role in their learning by leaving room to elicit feedback. 
As mentioned above, Habitus, like all sociological, cultural, and critical theories is not a blanket template to be applied to a set of data, but is a, to paraphrase art historian John Berger, a way of seeing, that opens the door to new questions and ways of thinking through perceived problems. As such, what Bourdieu's theory allows is for librarians to see the problem of students not understanding how to use library resources from a different perspective and one of deeper cultural empathy. By understanding some of the multidimensional nature of either student resistance towards library resources, or a lack of understanding, we can better understand the positionality of library instruction to best serve their needs. This attitudinal adjustment on the part of librarians may go some distance in removing some of the didactic barriers inherent when approaching the issue as a problem to be solved, as opposed to experience to be gained and incorporated into a unique and rich personal student epistemology.

The combination of a mixed adoption of the theories developed by both Schlossberg and Bourdieu respectively point towards a holistic student model that accounts for the difficulty of change and the shift in cultural language on students. As indicated through the lack of familiarity with many core library services and concepts, early college students may lack crucial skills to succeed in their courses. This lack of skills may be compounded with additional factors which should be increasingly considered as a facet of instruction as discussed largely in critical information literacy literature. Our innovative addition is the use of the theories mentioned above in combination with the first-generation student population focus. 


\section{References}

Barnes, W., \&, J. R. (2013). College-readiness is not one-size-fits-all. Current Issues in Education, 16 (1), 13.

Bereiter, C. (1995). A dispositional view of transfer. In A. McKeough, J. Lupart, \& A. Marini (Eds.), Teaching for transfer: Fostering generalization in learning (pp. 21-35). Mahwah, NJ: Lawrence Erlbaum.

Black, E. L., \& Murphy, S. A. (2017). The out loud assignment: Articulating library contributions to first-year student success. The Journal of Academic Librarianship 43 (5), 409-16. https://doi.org/10.1016/j.acalib.2017.06.008.

Bourdieu, P. (1980). Outline of a theory of practice. (R. Nice, Trans.). Stanford, CA: Stanford

Bourdieu, P. (1984). Distinction: A social critique of the judgement of taste. (R. Nice, Trans.). Harvard University Press.

Bourdieu, P. (1991). Language and symbolic power. (J. Thompson, Ed.). G. Raymond \& M. Adamson, Trans.). Harvard University Press.

Conley, D. T. (2008). Rethinking college readiness. New Directions for Higher Education (144), 3-13. https://doi.org/10.1002/he.321.

Crowley, B. (2005). Spanning the theory-practice divide in library and information science. Scarecrow Press.

Dansereau, D. F. (1995). Derived structural schemas and the transfer of knowledge. In A. McKeough, J. Lupart, \& A. Marini (Eds.) Teaching for transfer: Fostering generalization in learning (pp. 93-123). Lawrence Erlbaum.

Doherty, J. (2008). Towards self-reflection in librarianship: What is praxis? In A. Lewis, (ed.) Questioning library neutrality: Essays from progression librarianship (pp. 110-18). Library Juice.

Donham, J. (2014). College ready: What can we learn from first-year college assignments? An examination of assignments in Iowa colleges and universities. School Library Research, $17(21)$.

Dumais, S. A., \& Ward, A. (2010). Cultural capital and first-generation college success. Poetics 38 (3), 245-65. https://doi.org/10.1016/j.poetic.2009.11.011.

Duval, J. (2015). A heuristic tool: On the use and of the concept of the field in two studies in the sociology of culture. In Hilgers, M. \& Mangez, E. (Eds.) Bourdieu's theory of social fields: Concepts and applications (pp.165-81). Routledge. 
Edgerton, J. D., \& Roberts, L.W. (2014). Cultural capital or Habitus? Bourdieu and beyond in the explanation of enduring educational inequality. Theory and Research in Education, 12 (2), 193-220. https://doi.org/10.1177/1477878514530231.

Elmborg, J. (2012). Critical information literacy: Definitions and challenges. In Wilkinson (Ed.) Transforming information literacy programs: Intersecting frontiers of self, library culture, and campus community (pp. 75-95). ACRL.

Foster, E. (2018). Cultural competence in library instruction: A reflective practice approach. Portal: Libraries and the Academy, 18 (3). 575-93. https://doi.org/10.1353/pla.2018.0034.

Gaddis, M.S. (2013). The influence of Habitus in the relationship between cultural capital and academic achievement. Social Science Research, 42 (1). 1-13. https://doi.org/10.1016/j.ssresearch.2012.08.002.

Gaha, U., Hinnefeld, S., \& Pellegrino, C. (2018). The academic library's contribution to student success: Library instruction and GPA. College \& Research Libraries, 79 (6), 737-46. https://doi.org/10.586o/crl.79.6.737.

Garcia, K. (2015, June). Keeping up with...critical librarianship. Association of College and Research Libraries. https://www.ala.org/acrl/publications/keeping_up_with/critlib

Gergen, K. (1999). An invitation to social construction. Sage.

Gremmels, G.S. (2015). Constance Mellon's 'Library Anxiety’: An appreciation and a critique. College \& Research Libraries, 76 (3), 268-75. https://doi.org/10.5860/crl.76.3.268.

Haddow, G. (2013). Academic library use and student retention: A quantitative analysis. Library \& Information Science Research, 35 (2), 127-36. https://doi.org/10.1016/j.lisr.2012.12.002.

Henderson, T. (2018). Undergraduate socialization in engineering: The role of institutional tactics and proactive behaviors. In ASEE Annual Conference and Exposition Proceedings. ASEE.

Hess, A. N., Greer, K., Lombardo S. V., and Lim, A. (2015). Books, bytes, and buildings: The academic library's unique role in improving student success. Journal of Library Administration, 55 (8), 622-38. https://doi.org/10.1080/01930826.2015.1085241.

Hussey, L. (2010). Social capital, symbolic violence, and fields of cultural production: Pierre Bourdieu and library and information science. In G.J. Leckie, L. Given, \& J.E. Buschman (Eds.) Critical theory for library and information science: Exploring the social from across disciplines (pp. 41-53). Libraries Unlimited.

King, A. (2000). Thinking with Bourdieu against Bourdieu: A 'practical' critique of the Habitus. Sociological Theory, 18 (3), 417-33. 
Krutkowski, S. (2017). A strengths-based approach to widening participation students in higher education. Reference Services Review, 45 (2), 227-41. https://doi.org/10.1108/RSR-102016-0070.

Kuglitsch, R. Z. (2015). Teaching for transfer: Reconciling the framework with disciplinary information literacy. Portal: Libraries and the Academy, 15 (3), 457-70. https://doi.org/10.1353/pla.2015.0040.

Ladson-Billings, G. (1994). The Dreamkeepers. Jossey-Bass.

Leckie, G. J., Given, L., \& Buschman, J.E. (Eds.) (2010). Critical theory for library and information science: Exploring the social from across the disciplines. Libraries Unlimited.

Lewis, H. B. (1971). Shame and guilt in neurosis. International University Press.

Marini, A., \& Genereux, R. (1995). The challenge of teaching for transfer. In A. McKeough, J. Lupart, \& A. Marini (Eds.) Teaching for transfer: Fostering generalization in learning (pp. 1-12). Lawrence Erlbaum.

McAfee, E. (2018). Shame: The emotional basis of library anxiety. College \& Research Libraries, 79 (2), 237-56. https://doi.org/10.5860/crl.79.2.237.

Mellon, C. A. (1986). Library anxiety: A grounded theory and its development. College \& Research Libraries, $47(2)$.

Miller, W. (2013). Libraries and student success. Library Issues, 34 (2).

Morrison, K. L. (2017). Informed asset-based pedagogy: Coming correct, counter-stories from an information literacy classroom. Library Trends, 66 (2): 176-218. https://doi.org/10.1353/lib.2017.0034.

Murray, A., Ireland, A., \& Hackatorn, J. (2016). The value of academic libraries: Library services as a predictor of student retention. College \& Research Libraries, 77 (5), 631-41.

Nash, R. (1999). Bourdieu, 'Habitus', and educational research: Is it all worth the candle? British Journal of Sociology of Education 20 (2), 175-87. https://doi.org/10.1080/01425699995399.

Pai, Y., Adler, S.A., \& Shadiow, L.K. (2006). Cultural foundations of education. Merrill/Prentice-Hall.

Reay, D. (2001). Finding or losing yourself?: Working-class relationships to education. Journal of Education Policy, 16 (4), 333-46. https://doi.org/10.1080/02680930110054335.

Reay, D. (2004). 'It's all becoming a Habitus': Beyond the habitual use of Habitus in educational research. British Journal of Sociology of Education, 25 (4), 431-44. https://doi.org/10.1080/0142569042000236934. 
Reay, D., Crozier, G., \& Clayton, J. (2010). 'Fitting in' or 'standing out': Working-class students in UK higher education. British Educational Research Journal, 36 (1), 107-24. https://doi.org/10.1080/01411920902878925.

Schlossberg, N. (1981). A model for analyzing human adaption to transfer. The Counseling Psychologist, 9 (2), 2-18.

Silva, E. B. (2016). Habitus: Beyond sociology. The Sociological Review, 64 (1), 73-92. https://doi.org/10.1111/1467-954X.12345.

Smith, L. (2013). Towards a model of critical information literacy instruction for the development of political agency. Journal of Information Literacy, 7 (2). https://doi.org/10.11645/7.2.1809.

Soria, K. M., Nackerud, S., \& Peterson, K. (2015). Socioeconomic indicators associated with first-year college students' use of academic libraries. The Journal of Academic Librarianship, 41 (5), 636-43. https://doi.org/10.1016/j.acalib.2015.06.011.

Talja, S. (2005). The social and discursive construction of computing skills. Journal of the American Society for Information Science and Technology, 56 (1), 13-22. https://doi.org/10.1002/asi.20091.

Tewell, E. (2015). A decade of critical information literacy: A review of the literature. Communications in Information Literacy, 9 (1), 24. https://doi.org/10.1576o/comminfolit.2015.9.1.174.

Thorpe, A., Lukes, R., Bever, D.J. \& He, Y. (2016). The impact of the academic library on student success: Connecting the dots. Portal: Libraries and the Academy, 16 (2), 373-92. https://doi.org/10.1353/pla.2016.0027.

Tramonte, L, \& Willms, J.D. (2010). Cultural capital and Its effects on education outcomes. Economics of Education Review, 29 (2), 200-213. https://doi.org/10.1016/j.econedurev.2009.06.003.

Weidman, J. (1989). Undergraduate socialization: A conceptual approach.” In J.C. Smart (Ed.) Higher education: Handbook of theory and research (pp. 289-322). Agathon Press.

Wiecko, F. M. (2010). Research note: Assessing the validity of college samples: Are students really that different?” Journal of Criminal Justice, 38 (6), 1186-90. https://doi.org/10.1016/j.jcrimjus.2010.09.007.

Yan, M.C., \& Wong, Y.R. (2005). Rethinking self-awareness in cultural competence: Toward a dialogic self in cross-cultural social work. Families in Society: The Journal of Contemporary Social Services, 86 (2), 181-88. https://doi.org/10.1606/10443894.2453 . 


\section{Appendix}

The following is a text representation of our survey which we administered and analyzed using RedCap.

\section{Hello Terps!}

We are conducting a short survey to get to know your unique needs a little better and to see if there is anything the library can be helping you with. We are particularly interested in learning about the experiences of first-generation students (the first in your immediate family to go to college) and transfer students (from another university or community college). We are seeking to understand your needs and expand our views of the student population. By helping us hear your voice, we can learn more about how we can help you better or differently and to gauge your usage of libraries. This is a voluntary and anonymous survey and should take no longer than 15 minutes to complete.

Please consider helping your library hear your voice!

This survey should take no longer than 15 minutes to complete.

\section{Library Resources for First Generation Students}

Through this brief survey we are looking to understand your needs as a student and how the library can better serve you. By answering the following questions, you will help us to better suit your specific needs. As you know, students come to the university from many different backgrounds and with a diverse set of experiences and we are looking to expand our view of the typical student by listening to your individual needs. We will be using the data collected from this survey in a formal research project, but no identifying information will be recorded or in any way used. The anonymous data collected through this survey will be securely housed in a secure cloud storage solution maintained by the University of Maryland Division of IT. Additionally, this survey will have no bearing on your grade in a direct or indirect manner nor are your being compelled in any way to participate. By checking the box below, you are acknowledging and consenting to the above purposes, rationale, and conditions for this survey and are over the age of 18 .

Thank you very much!

1. How old are you?

2. What is your first language?

3. Are there any groups or clubs that you have identified that you would like to join on campus?

4. Why did you apply to the University of Maryland? 
5. Are you the first person in your immediate family to attend a four-year institution?

6. Are you transferring from another university or community college?

7. List three adjectives you would use to describe yourself to your professors?

1.

2.

3.

8. What are some of your anxieties about starting university?

9. From this list, circle the 5 things that are most important to you right now.

Making my parents proud

Making friends

Learning more about myself

Making good grades

Wanting to be intellectually challenged

Learning about new and interesting things

Traveling to new places

Learning about job/career opportunities

Making an impact in my community

Other:

10. Now choose the 3 most important things and rank them (with 1 being most important).

1.

2.

3.

11. How often would you say you used your high school library?

My school didn't have a library

Never used it (follow up)

1-2 times per year 

A about once a month
more than once a month
At least once per week

12. Which of these terms are you unfamiliar with?

Interlibrary Loan (ILL)

Subject Librarian

Archives

Library instruction

citation

reference manager

call number

Archivist

peer review

journal article

academic advisor

mentor

Makerspace

database

scholarship

plagiarism

self-plagiarism

reference

reference desk

catalog

commons

13. Do you currently use the library for any of the following reasons (select all that apply):

I don't use the library

A place to study/complete homework

Relax/Meditate 
Pick up a snack

Use the internet to complete coursework

Group projects

Use technology (list examples)

14. Is there anything else you would like us to know about your feelings regarding entering the university, preparing for assignments, studying, using the library, or any other topics important to you? 